\title{
Towards New Material Biomarkers for Fracture Risk
}

C. Greenwood ${ }^{\mathrm{a}}$, J. Clement ${ }^{\mathrm{b}}$, A. Dicken ${ }^{\mathrm{c}}$, J.P.O. Evans ${ }^{\mathrm{c}}$, I. Lyburn ${ }^{\mathrm{d}}$, R.M. Martin ${ }^{\mathrm{e}}$, K. Rogers ${ }^{\mathrm{a}}$, N. Stone ${ }^{\mathrm{f}}$ and P. Zioupos ${ }^{\mathrm{a}}$

${ }^{a}$ Cranfield Forensic Institute, Cranfield University, Defence Academy of the UK, Shrivenham, UK.

${ }^{b}$ Forensic Odontology, Melbourne Dental School, University of Melbourne, Melbourne, Australia.

${ }^{c}$ The Imaging Science Group, Nottingham Trent University, Nottingham, UK.

${ }^{d}$ Cobalt Health, Cheltenham, UK.

${ }^{e}$ Social and Community Medicine, Bristol University, Bristol, UK.

${ }^{f}$ Physics and Astronomy, Exeter University, Exeter, UK.

\begin{abstract}
Osteoporosis is a prevalent bone condition, characterised by low bone mass and increased fracture risk. Currently, the gold standard for identifying osteoporosis and increased fracture risk is through quantification of bone mineral density (BMD) using dual energy X-ray absorption (DEXA). However, the risk of osteoporotic fracture is determined collectively by bone mass, architecture and physicochemistry of the mineral composite building blocks. Thus DEXA scans alone inevitably fail to fully discriminate individuals who will suffer a fragility fracture. This study examines trabecular bone at both ultrastructure and microarchitectural levels to provide a detailed material view of bone, and therefore provides a more comprehensive explanation of osteoporotic fracture risk. Physicochemical characterisation obtained through X-ray diffraction and infrared analysis indicated significant differences in apatite crystal chemistry and nanostructure between fracture and non-fracture groups. Further, this study, through considering the potential correlations between the chemical biomarkers and microarchitectural properties of trabecular bone, has investigated the relationship between bone mechanical properties (e.g. fragility) and physicochemical material features.
\end{abstract}

Keywords: aging, bone quality, hydroxyapatite, osteoporosis, trabecular bone, X-ray diffraction 


\section{Introduction}

Osteoporosis affects approximately 200 million women around the world. In the UK alone $50 \%$ of women will suffer a fracture after the age of 50 [1], a rate which is annually increasing due to the aging population. Osteoporotic fractures often occur in the hip, wrist and vertebrae; although studies have shown hip fractures have the greatest detrimental effect on an individual [2]. Hip fractures result in a significant loss of independence, and sufferers are unable to live without support as they cannot walk unaided or perform many of their daily activities. Worryingly, hip fractures are often associated with increased mortality [3, 4], a statistic which is confounded by the asymptomatic nature of osteoporosis. Osteoporosis is often assessed according to an individual's bone mineral density (BMD) [5]. With a decrease in BMD, the risk of fracture is significantly increased [6]. Currently the gold standard for measuring BMD is through the use of dual energy X-ray absorption (DEXA). Unfortunately DEXA is not without limitations and is arguably a poor predictor of fracture, with a study carried out by Wainwright et al. showing that 54\% of new hip fractures occurred in women who did not have osteoporosis as determined by their BMD [7] and data from the National Osteoporosis Risk Assessment, showed that $82 \%$ of post-menopausal women with fractures had bone of 'normal' BMD [8]. The limitation of DEXA was perhaps highlighted with the development of FRAX, the World Health Organisation (WHO) fracture assessment tool, which uses BMD along with clinical risk factors and country-specific fracture and mortality data to quantify a patient's 10-year probability of a hip or major osteoporotic fracture [9]. FRAX takes into account demographic information such as age, sex, a prior fracture, family history of fracture, and lifestyles risk factors such as physical inactivity and smoking.

The limits associated with BMD to predict an individual patient's fracture risk is arguably because it does not measure the multiple material factors that contribute to bone strength [10]. There are several complex determinants of bone strength and fragility, and although properties which may increase the resistance to one type of mechanical demand, for example static loading, may also be detrimental to other kinds such as fatigue loading [11]. For this reason, material scientists differentiate between stiffness: how well a material resists deformation, toughness: the ability of a material to absorb energy prior to failure and strength: the ability of a material to resist failure when stretched or compressed. In this manuscript, strength refers to the ability of the material to withstand loading before structural failure occurs. The assumption is that bone strength is lower for the fracture group than that of the non-fracture group. Further mechanical testing would be required to establish whether 
bone chemistry parameters investigated in this study are independently correlated to stiffness, toughness or strength.

In this context, bone strength is a combination of bone density as well as 'bone quality', whereby bone quality refers to bone architecture (i.e. macro and micro) and bone chemistry [10]. A small number of studies (possibly due to the difficulty of obtaining human bone, especially osteoporotic specimens) have shown microarchitectural properties of bone potentially offer a superior way to differentiate between diseased bone (due to osteoporosis or osteoarthritis) when compared to healthy controls [12 - 14]. This has recently led to the investigation of various imaging techniques including high-resolution peripheral quantitative computed tomography (HR-pQCT) and the development of analytical tools such as trabecular bone score (TBS). Unfortunately, HR-pQCT is restricted to peripheral skeletal sites and therefore the lumbar spine or proximal femur (common sites for osteoporotic fragility fractures which are associated with the most significant quality of life burden for patients) cannot be imaged with this technique [15]. TBS, which captures information relating to trabecular microarchitecture by performing novel grey-level texture measurements on DEXA images [16], is undoubtedly promising; however, this tool quantifies the micro architecture of the bone only and does not account for bone chemistry.

Bone chemistry is more complex, with studies often providing contradicting results and conclusions [17 - 23]. Unfortunately, many of the studies which investigate the chemistry of osteoporotic bone are limited by relatively low sample numbers $(\mathrm{n} \leq 10$ for both osteoporotic and 'normal' specimens) $[20,24,25]$ and/ or utilise ovariectomized (Ovx) animal models [26, 27]. Exceptionally, a more recent study by Boskey [22], investigated the material properties of a large number of cortical and trabecular specimens $(n=120)$ using Fourier transform infrared spectroscopy (FTIR). The bone specimens were collected from the iliac crest (as a proxy for fractures at other sites) between 6 months and 5 years after a fracture. Several previous studies have examined the physicochemical properties of the inorganic bone component (i.e. the hydroxyapatite mineral) characterised by X-ray diffraction (XRD) [17, $24,25]$ and the organic component (i.e. collagen) as characterised by Raman spectroscopy $[28,29]$ or Fourier transform infra-red spectroscopy (FTIR) [26, 30 - 33]. Perhaps of most relevance are those reports detailing differences between osteoporotic and 'normal' tissues, although inconsistencies are frequent. For example, reports such as those of Thompson et al [17] and Faibish and Boskey [34] suggested an increase in crystallite size in osteoporotic 
tissue. However, these two reports differ in conclusions regarding the crystal chemistry; Thompson suggested a decrease in carbonate [17], while Faibish and Boskey [34] argued for an increase when comparing osteoporotic to normal bone. An increase in both crystallite size and carbonate content was reported by Gadeleta et al [18]. Several reports have been unable to demonstrate significant differences between osteoporotic and normal bone tissue when considering crystallite size [20, 27, 35] although a review by Boskey in 2003 reported that the general consensus accepts that osteoporotic bone mineral has larger crystallites than the nonosteoporotic counterparts [19]. It is evident from the literature this view point is contentious. A more recent study by Boskey et al. [22] reported a decrease in carbonate to phosphate ratios in fractured bone compared to non-fractured cortical bone, suggesting either a decrease in carbonate and/ or an increase in phosphate. No other differences were observed for either cortical or trabecular bone. In contrast, McCreadie et al. reported an increase in the carbonate to phosphate ratio between specimens collected from women with and without osteoporotic fractures [28].

There have been a few studies that have examined changes to the hydroxyapatite unit cell parameters (as a proxy for lattice substitutional modifications) of osteoporotic and/or aged bone mineral $[35,36]$. The major substitution in biological hydroxyapatite is carbonate, which substitutes for the hydroxyl (A - type) and/ or phosphate (B-type) in the crystal lattice or exists on the apatite surface (labile carbonate) [37, 38]. In general, a decrease in ' $a$ ' axis and an increase in the 'c' axis lattice parameters has been reported with age [36]. These trends are consistent with increased in B-type carbonate substitution [37] observed in synthetic apatites. In contrast other studies were unable to detect differences in the lattice parameters of osteoporotic bone [35]. As a further bone characteristic measured by FTIR, it has been reported that for osteoporotic tissues the mineral to organic ratio is lower than that of normal bone $[18,30]$. Thus in general, the literature contains several previous studies of bone physicochemical characteristics but these very often provide apparently conflicting findings and results. This, in the context of our work, is considered in further detail within our Discussion section.

The study described herein reports the physicochemical properties assessed using XRD and FTIR for trabecular bone obtained from the femoral head of individuals who suffered a femoral neck fracture and from a corresponding group where no fracture was reported. Further to this investigation, the data provided an opportunity to explore relationships 
between the ultrastructure material building blocks and the derived architectural properties. Thus the potential relationship between the bone mineral chemical properties - and the micro architectural properties of bone was investigated. This novel component of the work only involved the fracture group as relatively large deviations in architecture would be expected in this group.

\section{Materials and Methods}

\section{Bone Specimens}

A sample set of 20 femoral heads were collected from osteoporotic female patients who had suffered fragility fractures at the femoral neck and consequently required hip replacement surgery. Of these 20 , the donor's age was available for 16 of the femoral heads, ranging from 59 - 91 years old. Ethical approval for the collection and use of these specimens was provided by Gloucestershire NHS trust REC. Non-fracture femoral head specimens were collected from 39 female donors within the Melbourne Femur Collection. All donors from this source were coronial cases and had therefore died suddenly and unexpectedly as result of accidents. Ethical approval for the collection and use of these specimens was provided by Melbourne University. Population characteristics for both fracture and non - fracture specimens are provided in Table 1.

\begin{tabular}{|c|c|c|c|c|c|}
\hline & \multirow[b]{2}{*}{ Fracture } & \multirow[b]{2}{*}{$\begin{array}{c}\text { Non- } \\
\text { Fracture }\end{array}$} & \multicolumn{2}{|c|}{$\begin{array}{c}\text { Age Matched } \\
(70+\text { years })\end{array}$} & \multirow[b]{2}{*}{ p-value } \\
\hline & & & Fracture & $\begin{array}{c}\text { Non- } \\
\text { Fracture }\end{array}$ & \\
\hline Donors & 16 & 39 & 15 & 21 & \\
\hline Age Range (yrs) & $59-91$ & $20-90$ & $73-90$ & $71-90$ & \\
\hline Age Mean (yrs) & $82.4 \pm 6.4$ & $66.1 \pm 17.9$ & $82.5 \pm 4.1$ & $79.4 \pm 5.4$ & 0.064 \\
\hline Weight Range (kg) & $41-79$ & $40-121$ & $41-79$ & $49-87$ & \\
\hline Weight Mean (kg) & $61.1 \pm 8.9$ & $66.7 \pm 19.7$ & $60.8 \pm 9.1$ & $63.69 \pm 13.0$ & 0.494 \\
\hline Stature Range (cm) & $155-173$ & $145-169$ & $155-173$ & $146-169$ & \\
\hline Stature Mean $(\mathrm{cm})$ & $163.9 \pm 5.2$ & $159.6 \pm 6.7$ & $164.3 \pm 5.1$ & $159.6 \pm 7.1$ & 0.060 \\
\hline
\end{tabular}

Table 1: Population characteristics for the fracture and non-fracture groups including characteristics once age matched $(70+$ years $)$. The standard deviations for all mean values are provided. $\mathrm{p}$ - values are provided for comparison of the age matched data (age, weight 
and stature) for the two groups. $\mathrm{p}$ - values were calculated using a t-test, with a confidence level of $95 \%$, after assessing normality and differences in variances. Note weight and stature data was only available for $n=24$ for all the non - fracture donors and $n=13$ for the age matched non-fracture donors.

\section{Sample Preparation}

Trabecular bone was obtained and analysed for this study from the femoral head. Overall the strategy was to select random samples with respect to femoral head location although each sample was cut to include tissue from at least two quadrants of the head. The femoral head is often defined into four quadrants: anterior, posterior, inferior and superior [39, 40]. It is important to note that samples were obtained from trabecular bone only, and did not include cortical bone. For a complete description of the sampling and sectioning procedure refer to [41 - 43]. Prior to data collections, the specimens were homogenised using a Retsch mixer miller (mm 2000) and a zirconium oxide milling basket and ball. The specimens were cut into smaller sections, to reduce the number of milling cycles and milled for one minute. Once powdered, the specimens were sieved through a stainless steel mesh sieve of $106 \mu \mathrm{m}$ to ensure a homogenous fine powder sample.

\section{$X$-ray diffraction $(X R D)$}

The powdered trabecular bone specimens were individually loaded on to low background scattering (off-cut silicon) XRD holders. The bone powder was spiked with a NIST standard reference silicon powder (640c) to provide an internal standard required for determining accurate lattice parameters. XRD analysis was carried out using a PANalytical X'Pert PRO Multi-Purpose Diffractometer with $\mathrm{Cu} \mathrm{K \alpha}$ radiation. A PIXcel strip detector was used to collect data as stepped scans across an angular range of $15-802 \theta\left(^{\circ}\right)(5.90-1.20 \AA)$. The count time at each step was equivalent to $\sim 1$ second. Data was also collected for two further stepped scans under the sample conditions but across an angular range of $23-272 \theta\left({ }^{\circ}\right)(3.86$ - $3.30 \AA \mathrm{d}$-spacing) and $50-552 \theta\left({ }^{\circ}\right)(1.82-1.67 \AA \mathrm{d}$-spacing $)$, and with a count time at each step equivalent to $\sim 3$ seconds. The two additional stepped scans were collected to provide greater quality data for the 002 and 004 Bragg maxima respectively. This data was used to accurately calculate the full width half maximum (FWHM) of both the 002 and 004 Bragg maxima. The FWHM values were then used to calculate coherence length using the 
Scherrer equation, as described below. Bruker Topas software (Version 4.1, 2008) was employed to undertake profile fitting of each diffraction profile. This provided quantitative crystallite size and morphology parameters through calculation of the coherence length and structural parameters of the crystal lattice through the lattice parameters.

Coherence length was calculated for two orthogonal crystallographic directions, $<00 \ell>$ and $<0 \mathrm{k} 0\rangle$ using the Scherrer equation, which uses the instrument corrected, full width half maximum of the desired peak, as described in [44]. The lattice parameters were calculated from whole pattern fitting refinement of diffraction profiles to obtain the $2 \theta$ peak positions. Sample displacement was refined and lattice parameter data corrected accordingly. No unit cell content model was applied and analytical peak shapes were pseudo-Voigt. The data collection, correction and analyses were repeated three times for five randomly selected specimens to assess repeatability.

\section{Fourier Transform Infrared Spectroscopy (FTIR)}

FTIR analysis was carried out using an attenuated total reflectance (ATR) - FTIR. ATRFTIR reduces sample preparation as there is no requirement for preparation of potassium bromide $(\mathrm{KBr})$ pellets and the bone powder can be examined directly. This reduces potential contamination. Although ATR spectra measured by FTIR are similar to those collected by transmission measurements it is worth noting there are subtle differences. This is due to the wavelength dependency of the penetration depth in the sample and the anomalous dispersion of the IR-light. Consequently in ATR, which is a surface analysis technique, IR absorbance bands at long wavelengths will be of higher absorbance than those of shorter wavelength.

Approximately $2 \mathrm{mg}$ of homogenised bone powder ( 106 $\mu \mathrm{m}$ particle size) was used for analysis. Three x $2 \mathrm{mg}$ of bone powder per specimen was analysed to assess repeatability. FTIR spectra were collected using a Bruker Alpha Platinum ATR and analysis carried out using PerkinElmer Spectrum software. A scan resolution of $4 \mathrm{~cm}^{-1}$ and 16 scans was employed for data collection, within a range of $2500-400 \mathrm{~cm}^{-1}$.

FTIR analysis was employed to provide semi-quantitative data on the organic and carbonate content in the specimens. Following convention [45 - 48], the mineral: organic ratio was assessed through measuring the area of the $v_{3}$ phosphate $\left(1200-900 \mathrm{~cm}^{-1}\right)$ and the amide I 
$\left(1750-1600 \mathrm{~cm}^{-1}\right)$ bands. The carbonate: phosphate was assessed through measuring the area of the $\mathrm{v}_{2}$ carbonate $\left(890-850 \mathrm{~cm}^{-1}\right)$ and $\mathrm{v}_{3}$ phosphate bands.

\section{Micro Computed Tomography $(\mu$ - CT)}

The relationship between architectural properties and physicochemical parameters were investigated for this study. The architectural properties of the fracture specimens, obtained from $\mu$ - CT, have previously been reported, details of which can be found elsewhere [41]. Parameters such as trabecular number $(\mathrm{TbN})$, structure model index (SMI), trabecular thickness (TbTh), bone volume to total volume (BV/ TV) and tissue mineral density (TMD) were previously reported. It is important to note that the same specimens quantified using $\mu$ CT were pulverised once imaged and analysed for this study. Additional tissue from the same patient was not utilised.

\section{Statistical Analysis}

Linear regression analysis was carried out to statistically assess correlations between various material characteristics parameters and age for the non-fracture group. A general linear model ANOVA analysis was also undertaken to determine significant differences between the parameters measured for age matched fracture and non-fracture groups. Donors of age 70 years and greater were utilised for quantitative comparisons between the two groups, to avoid any bias arising from differences in age distributions. For the fracture group, $n=15$, as one donor, a 59 year old, was excluded from the age matched statistical analysis. For the non fracture group, $\mathrm{n}=21$ when age matching. $\mathrm{p}<0.05$ was considered statistically significant for both the linear regression and ANOVA analysis.

\section{Results}

This study reports the material quality of trabecular bone from human fracture and non fracture specimens, with the parameters analysed correlated to age. Further, the material quality parameters associated with the fracture specimens have been correlated to the microarchitecture properties (previously reported in [41]). This provides a more 
comprehensive understanding of how a change in the material chemistry can be associated with parameters such as trabecular number $(\mathrm{TbN})$, tissue mineral density (TMD), structure model index (SMI) and bone volume to total volume (BV/TV). The average values and associated errors of the material properties derived from both XRD and FTIR analysis are presented in table 2, along with the p-values associated with age matched ANOVA analysis of fracture $(n=15)$ and non-fracture groups $(n=21)$.

\begin{tabular}{|c|c|c|c|c|c|}
\hline & \multicolumn{2}{|c|}{ All Specimens } & \multicolumn{2}{|c|}{ Age Matched $(70+$ yrs $)$} & \multirow{2}{*}{$\begin{array}{c}\text { ANOVA } \\
\text { Non - } \\
\text { Fracture vs } \\
\text { Fracture } \\
\text { (Age } \\
\text { Matched) } \\
\text { p - value }\end{array}$} \\
\hline & Fracture & $\begin{array}{c}\text { Non - } \\
\text { Fracture }\end{array}$ & Fracture & $\begin{array}{c}\text { Non - } \\
\text { Fracture }\end{array}$ & \\
\hline $\mathbf{N}$ & 16 & 39 & 15 & 21 & - \\
\hline CL $00 \ell(\mathrm{nm})$ & $\begin{array}{l}\mathbf{2 7 . 5} \\
(0.6) \\
\end{array}$ & $\begin{array}{l}\mathbf{2 8 . 9} \\
(0.3) \\
\end{array}$ & $\begin{array}{l}\mathbf{2 7 . 4} \\
(0.4) \\
\end{array}$ & $\begin{array}{l}\mathbf{2 8 . 8} \\
(0.4) \\
\end{array}$ & 0.020 \\
\hline CL hk0 (nm) & $\begin{array}{c}\mathbf{8 . 2 4} \\
(0.10) \\
\end{array}$ & $\begin{array}{c}\mathbf{8 . 2 1} \\
(0.08) \\
\end{array}$ & $\begin{array}{c}\mathbf{8 . 2 5} \\
(0.09) \\
\end{array}$ & $\begin{array}{c}\mathbf{8 . 3 2} \\
(0.10) \\
\end{array}$ & 0.487 \\
\hline LP' 'a' axis $(\AA)$ & $\begin{array}{c}\mathbf{9 . 4 0 2} \\
(0.001)\end{array}$ & $\begin{array}{c}\mathbf{9 . 4 0 6} \\
(0.001)\end{array}$ & $\begin{array}{c}\mathbf{9 . 4 0 3} \\
(0.001)\end{array}$ & $\begin{array}{c}\mathbf{9 . 4 0 7} \\
(0.001)\end{array}$ & 0.002 \\
\hline LP'c' axis $(\AA)$ & $\begin{array}{c}\mathbf{6 . 8 9 6} \\
(0.0006) \\
\end{array}$ & $\begin{array}{r}\mathbf{6 . 8 9 5} \\
(0.002) \\
\end{array}$ & $\begin{array}{c}\mathbf{6 . 8 9 7} \\
(0.0004) \\
\end{array}$ & $\begin{array}{c}\mathbf{6 . 8 9 6} \\
(0.002) \\
\end{array}$ & 0.320 \\
\hline Mineral: Organic & $\begin{array}{c}\mathbf{7 . 1 0} \\
(0.08) \\
\end{array}$ & $\begin{array}{c}\mathbf{7 . 0 6} \\
(0.08) \\
\end{array}$ & $\begin{array}{c}\mathbf{7 . 0 2} \\
(0.03) \\
\end{array}$ & $\begin{array}{c}\mathbf{7 . 2 3} \\
(0.09) \\
\end{array}$ & 0.077 \\
\hline $\begin{array}{l}\text { Carbonate: } \\
\text { Phosphate }\end{array}$ & $\begin{array}{c}\mathbf{0 . 0 1 9 9} \\
(0.0004) \\
\end{array}$ & $\begin{array}{c}\mathbf{0 . 0 1 8 5} \\
(0.0002) \\
\end{array}$ & $\begin{array}{c}\mathbf{0 . 0 2 0 2} \\
(0.0003) \\
\end{array}$ & $\begin{array}{c}\mathbf{0 . 0 1 8 4} \\
(0.0003) \\
\end{array}$ & 0.000 \\
\hline
\end{tabular}

Table 2: Average values (in bold) and the associated errors ( \pm SEM) in brackets for the material parameters obtained from XRD and FTIR analysis, for fracture and non-fracture groups. $\mathrm{p}$ - values for age matched ANOVA analysis of fracture $(\mathrm{n}=15)$ and non-fracture groups $(n=21)$, for each material characteristic parameter are also provided. 


\section{X-ray Diffraction (XRD)}

Coherence length, which provides a quantitative estimate of crystallite size and strain combined (i.e. the total lattice disorder), did not change with age for the non - fracture group in the $<00 \ell>$ crystallographic direction, but was found to increase $(p=0.016)$ with age when the $\langle 0 \mathrm{k} 0\rangle$ direction was considered (Figure 1A). The coherence length values for the fracture group were lower $(\mathrm{p}=0.020)$ when age matched to the non - fracture group specimens in the $<00 \ell>$ direction (see Table 2). With increasing age, the lattice parameters associated with the 'a' axis and 'c' axis remain constant, within experimental errors, for the non - fracture group, ranging from approximately $9.40-9.41 \AA$ for the 'a' axis (Figure 1B) and $6.85-6.90 \AA$ for the 'c' axis. The 'a' axis lattice parameter values for the fracture group are less $(p=0.002)$ than those of the non - fracture group (see Table 2). No difference in the 'c' axis lattice parameters were observed between the two groups.

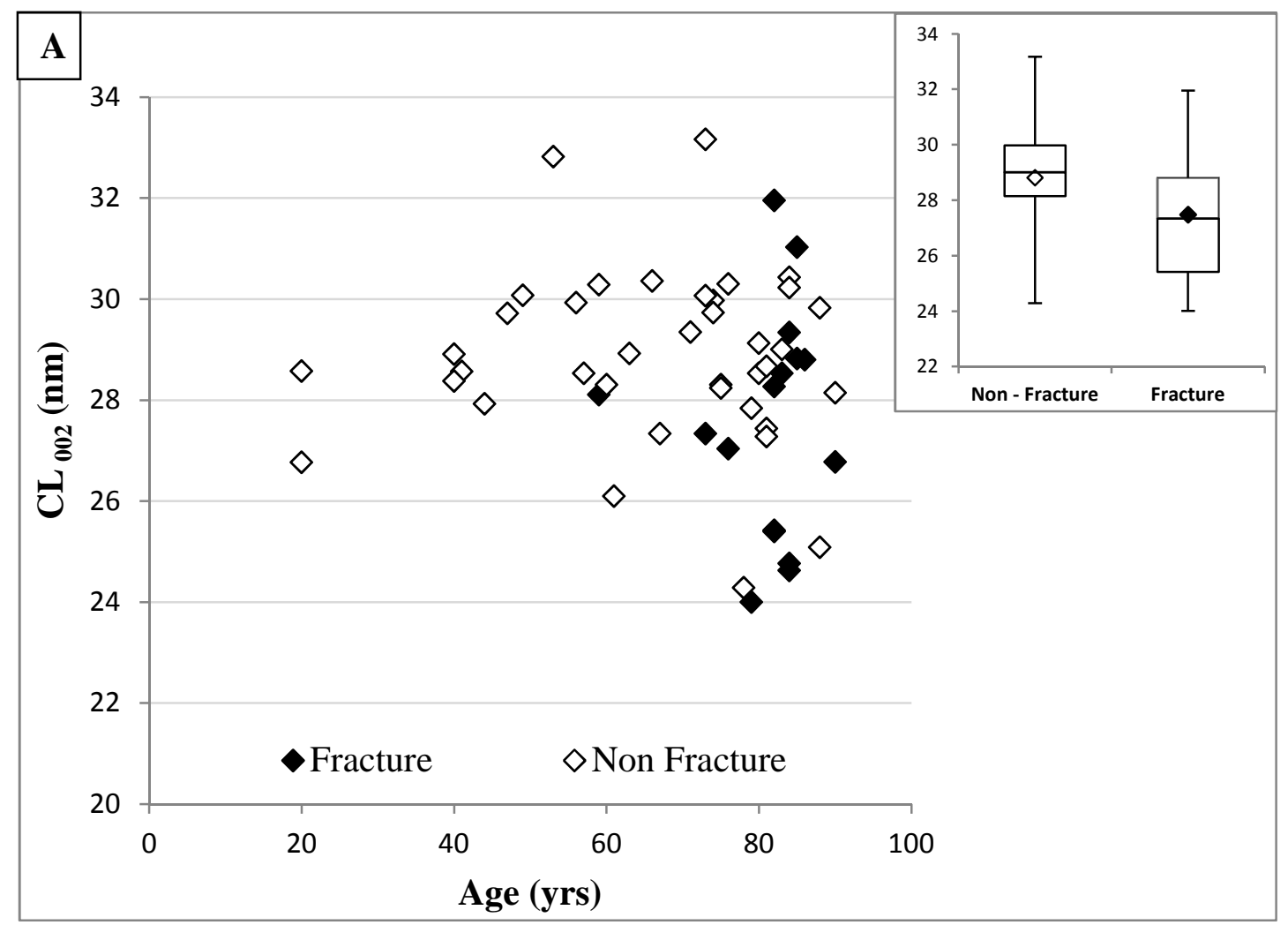




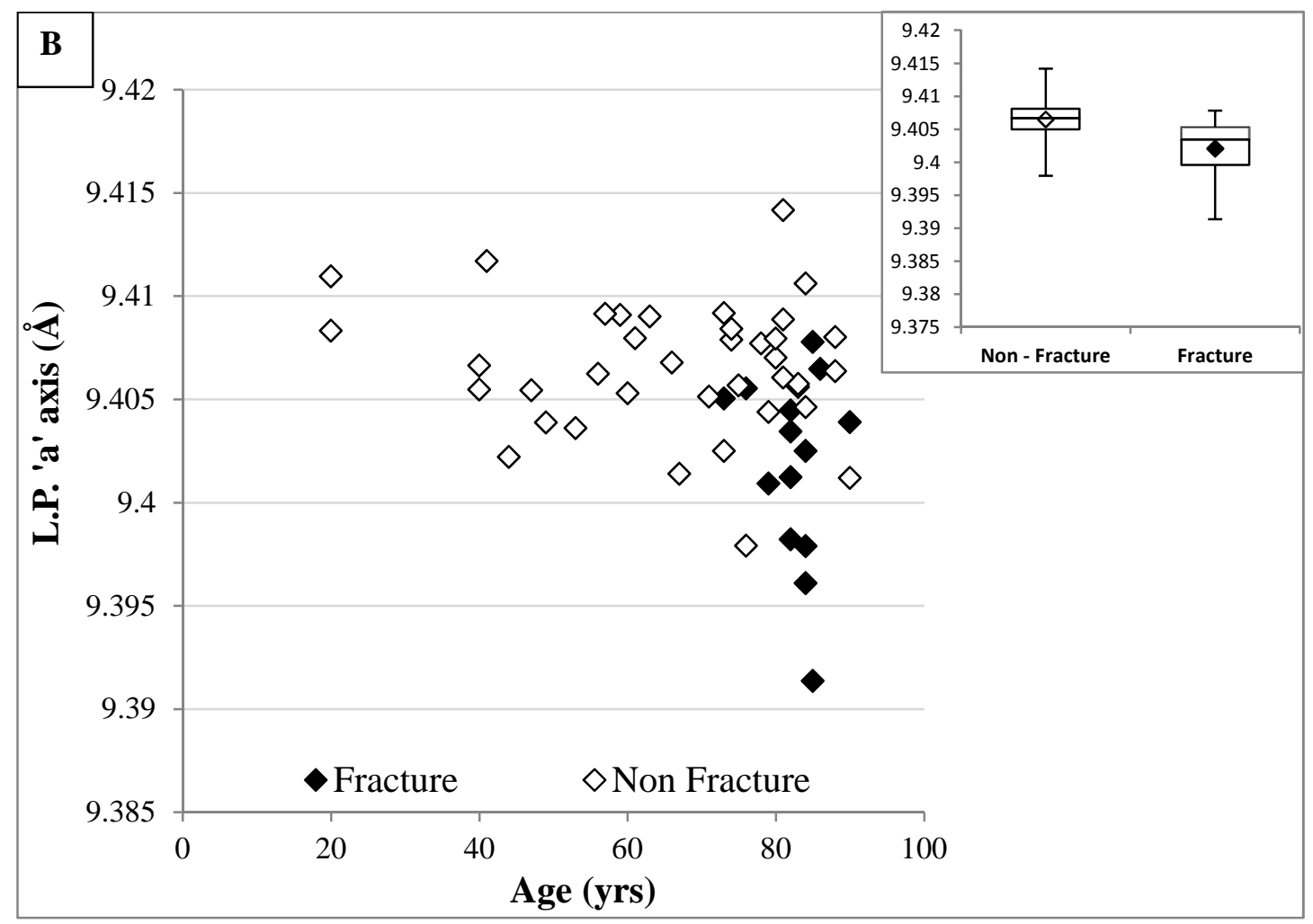

Figure 1: Relationship between XRD parameters and age (A: coherence length (CL) values along the $00 \ell$ direction vs age, B: ' $a$ ' axis lattice parameters vs age), for fracture and nonfracture specimens. Errors have been excluded from the graphs for clarity. Standard box and whisker plots for the age matched data $(70$ years + ) are included as inserts in each graph. The horizontal line within the box indicates the median, boundaries of the box indicate the $25^{\text {th }}$ and $75^{\text {th }}$ percentile, and the whiskers indicate the highest and lowest values of the results. The ' $\diamond$ ' marked in the box indicates the mean.

\begin{tabular}{|c|c|c|c|}
\hline & \multirow{2}{*}{\multicolumn{3}{|c|}{$\begin{array}{c}\text { Linear Regression Analysis } \\
\text { Non - Fracture Correlations with } \\
\text { Age }\end{array}$}} \\
\hline & & & \\
\hline & p - value & $\mathbf{R}^{2}$ & $\begin{array}{c}\Delta \\
\text { (per } 5 \text { yrs) }\end{array}$ \\
\hline $\begin{array}{l}\mathbf{C L}_{00 \ell} \\
(\mathbf{n m})\end{array}$ & 0.910 & 0.00 & - \\
\hline $\begin{array}{l}C_{\text {hk0 }} \\
\text { (nm) }\end{array}$ & 0.016 & 0.15 & $\begin{array}{c}0.050 \\
(0.020)\end{array}$ \\
\hline $\begin{array}{c}\text { LP 'a' } \\
\text { axis (̊̊) }\end{array}$ & 0.407 & 0.02 & - \\
\hline $\begin{array}{c}\mathbf{L P} \text { 'c' axis } \\
(\AA))\end{array}$ & 0.213 & 0.04 & - \\
\hline
\end{tabular}

Table 3: $\mathrm{p}$ - values and $\mathrm{R}^{2}$ calculated from linear regression statistical analysis when comparing the various XRD material characteristic parameters and age for the non-fracture 
group. For the parameters were a significant trend was observed, the rate of change $(\Delta)$ per 5 years is also reported. Associated errors are provided in brackets.

\section{Fourier Transform Infrared Spectroscopy (FTIR)}

The carbonate to phosphate ratio was found to be greater $(\mathrm{p}=0.000)$ for the fracture group in comparison to the non-fracture group, when age matched. No age related trends were observed for the non - fracture group (Figure 2A). The value of the mineral to organic ratio, which indicate an increase in collagen and/ or a reduction in phosphate, are presented in figure $2 \mathrm{~B}$ for both fracture and non - fracture groups. The variability in the mineral to organic ratio for the non - fracture group is evident. When age matched, the mineral: organic values are not different $(p=0.077)$ for the fracture group in comparison to the non - fracture group. However, with age, an increase in mineral to organic ratio values was observed ( $\mathrm{p}=$ 0.019) for the non-fracture group.

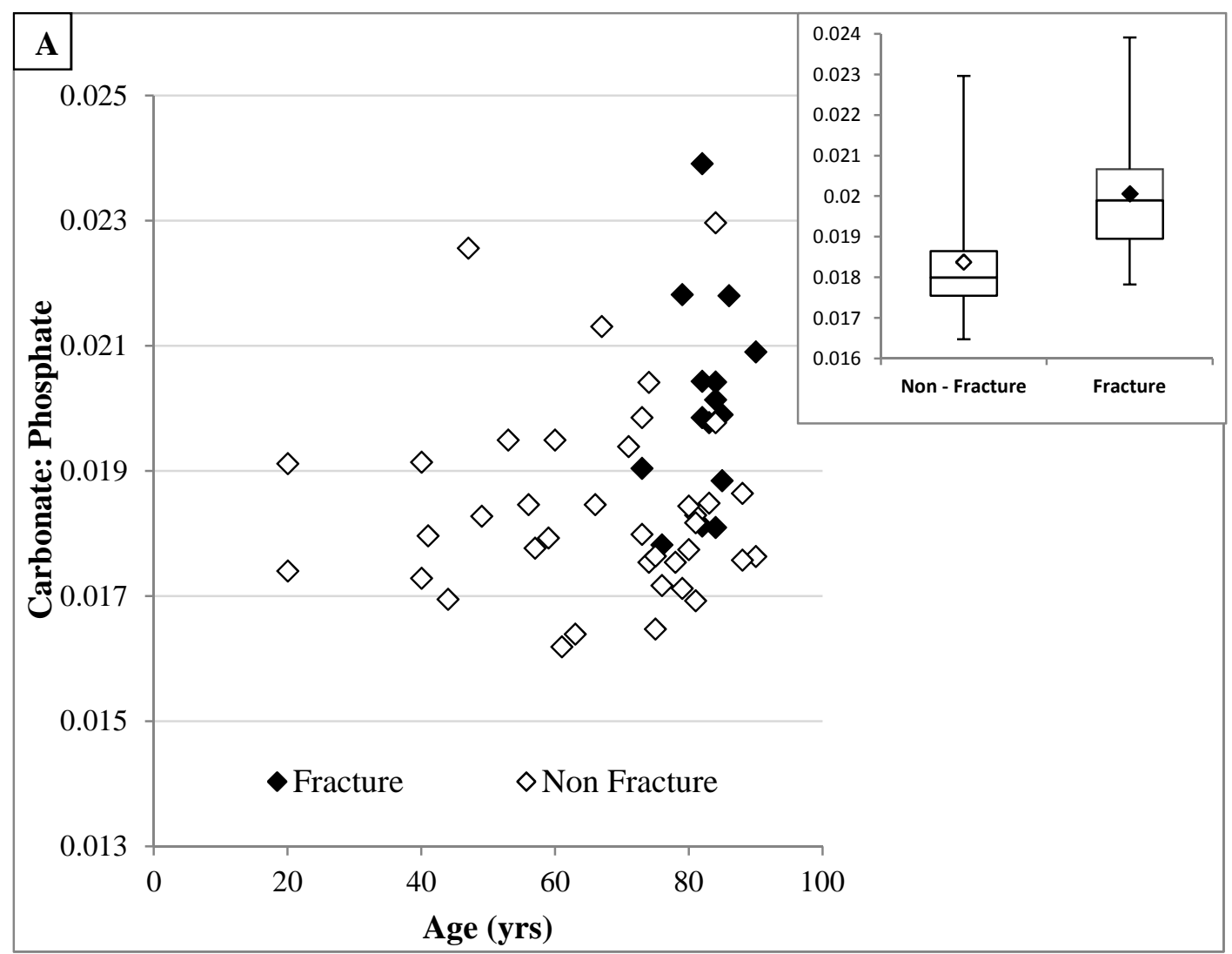




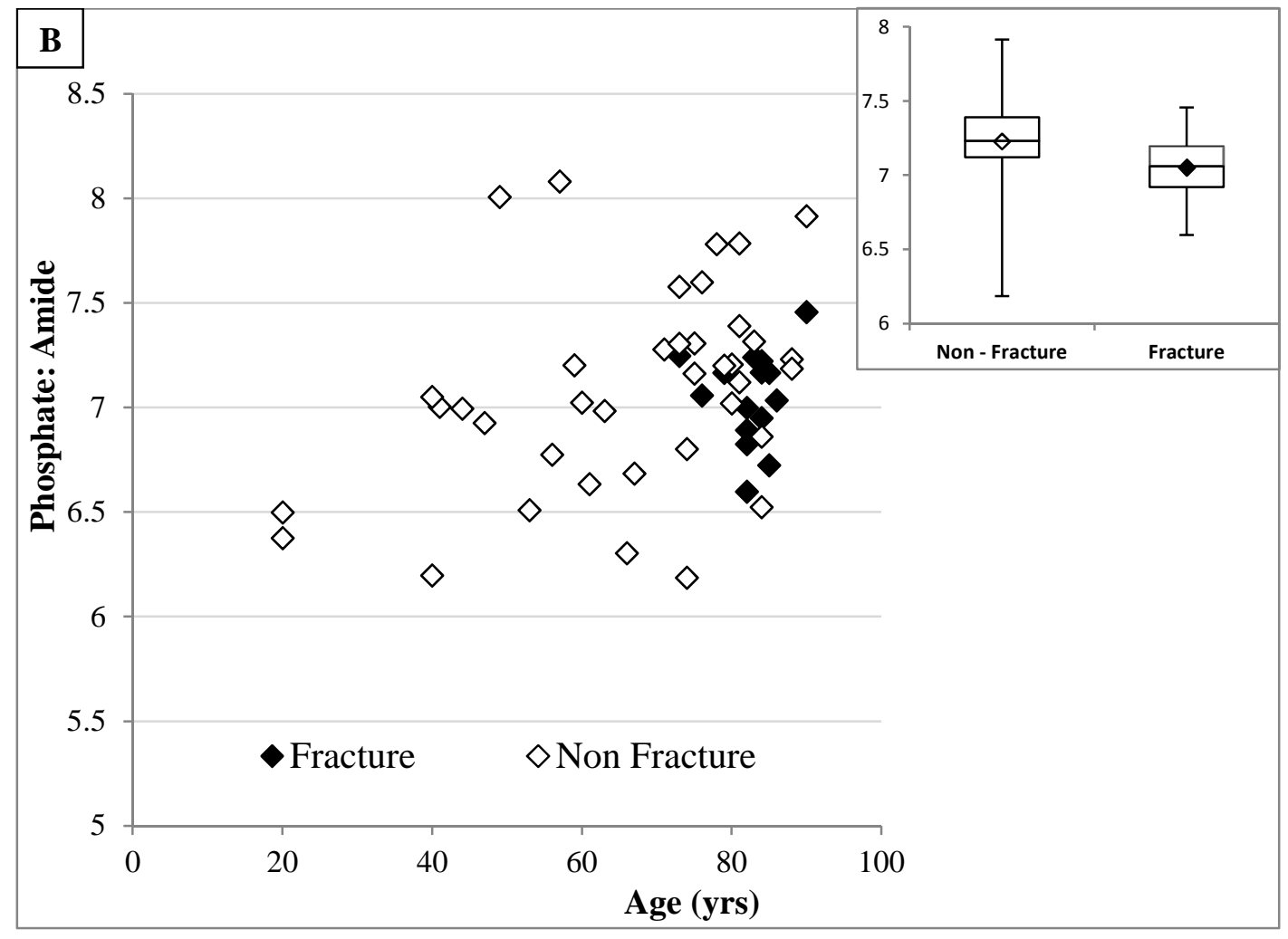

Figure 2: Relationship between FTIR parameters and age (A: carbonate: phosphate values vs age, B: Mineral: organic values vs age), for fracture and non-fracture specimens. Errors have been excluded from the graphs for clarity. Standard box and whisker plots for the age matched data (70 years + ) are included as inserts in each graph. The horizontal line within the box indicates the median, boundaries of the box indicate the $25^{\text {th }}$ and $75^{\text {th }}$ percentile, and the whiskers indicate the highest and lowest values of the results. The ' $\diamond$ ' marked in the box indicates the mean.

\begin{tabular}{|c|c|c|c|}
\cline { 2 - 4 } \multicolumn{1}{c|}{} & \multicolumn{3}{c|}{ Linear Regression Analysis } \\
\cline { 2 - 4 } \multicolumn{1}{c|}{} & \multicolumn{2}{c|}{$\begin{array}{c}\text { Non - Fracture Correlations with } \\
\text { Age }\end{array}$} \\
\cline { 2 - 4 } & $\begin{array}{c}\mathbf{p} \text { - } \\
\text { value }\end{array}$ & $\mathbf{R}^{2}$ & $\begin{array}{c}\boldsymbol{\Delta} \\
\text { (per 5 yrs) }\end{array}$ \\
\hline $\begin{array}{c}\text { Mineral: } \\
\text { Organic }\end{array}$ & $\mathbf{0 . 0 1 9}$ & 0.15 & $\begin{array}{c}0.051 \\
(0.020)\end{array}$ \\
\hline $\begin{array}{c}\text { Carbonate: } \\
\text { Phosphate }\end{array}$ & 0.978 & 0.00 & - \\
\hline
\end{tabular}

Table 4: $\mathrm{p}$ - values and $\mathrm{R}^{2}$ calculated from linear regression statistical analysis when comparing the various FTIR material characteristic parameters and age for the non-fracture group. For the parameters were a significant trend was observed, the rate of change $(\Delta)$ per 5 years is also reported. Associated errors are reported in brackets. 


\section{Microarchitecture and Material Characteristics}

We have also examined correlations between the material properties and the architectural properties for the fracture group, in order to explore the potential influence bone chemistry may have on the architecture of compromised specimens. There is significant evidence from previous studies that bone mechanical properties (e.g. fragility) are affected by physicochemical material features [18, 49 - 53], although there remains controversy concerning the precise nature and magnitude of such relationships. The composition of apatite is known to markedly affect its crystallite size and shape. For example phosphate substitution by carbonate (bone apatite contains $\sim 5 \%$ wt. $\mathrm{CO}_{3}{ }^{2-}$ ) results in smaller crystallites than the corresponding unsubstituted chemistry $[54,55]$, as the increase in lattice disorder produces increased solubility of the crystallites $[55,56]$.

\section{Coherence length}

$<00 \ell>$ coherence length values were found to correlate with various microarchitecture parameters previously reported for the fracture group (Figure 3). With increasing coherence length values, an increase in trabecular thickness (TbTh) $\left(p=0.028, R^{2}=0.24\right.$, Figure $\left.3 \mathrm{~A}\right)$, tissue mineral density (TMD) $\left(p=0.006, R^{2}=0.35\right.$, Figure $3 B$ ) and bone volume to total volume $(\mathrm{BV} / \mathrm{TV})\left(\mathrm{p}=0.036, \mathrm{R}^{2}=0.22\right)$.

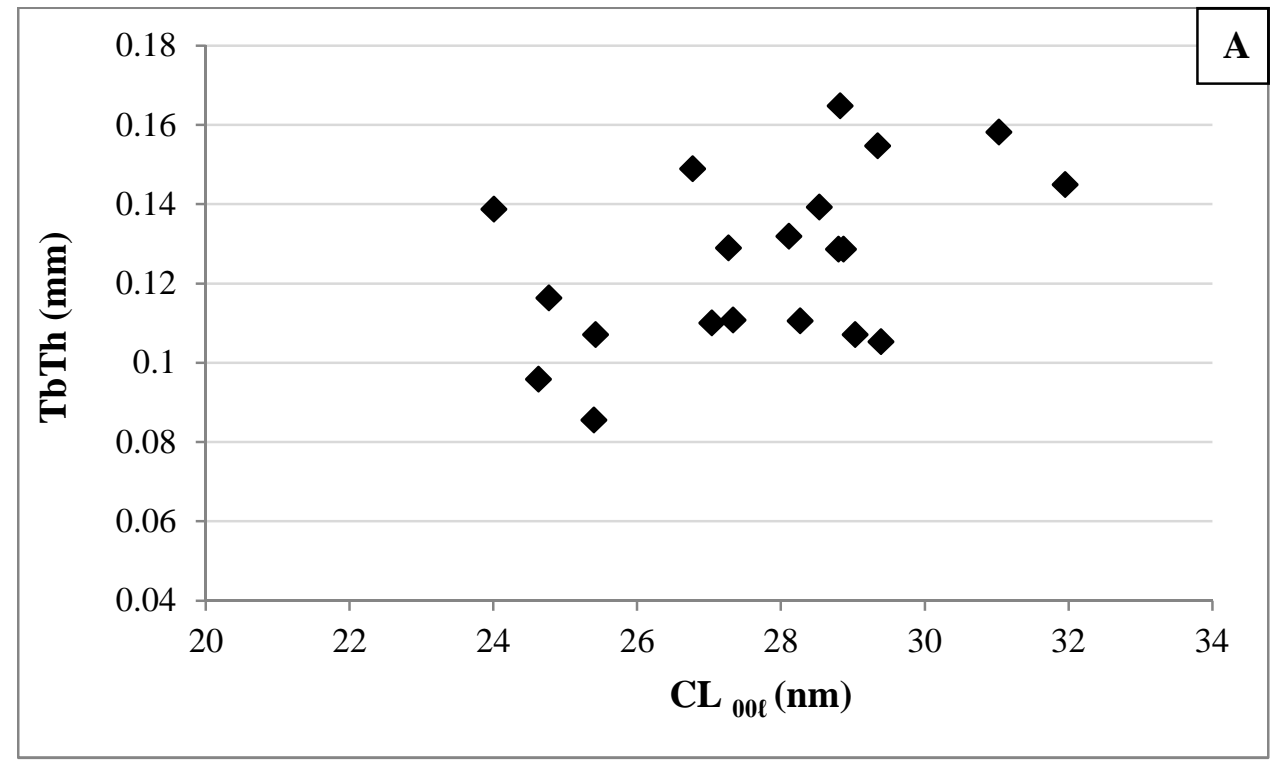




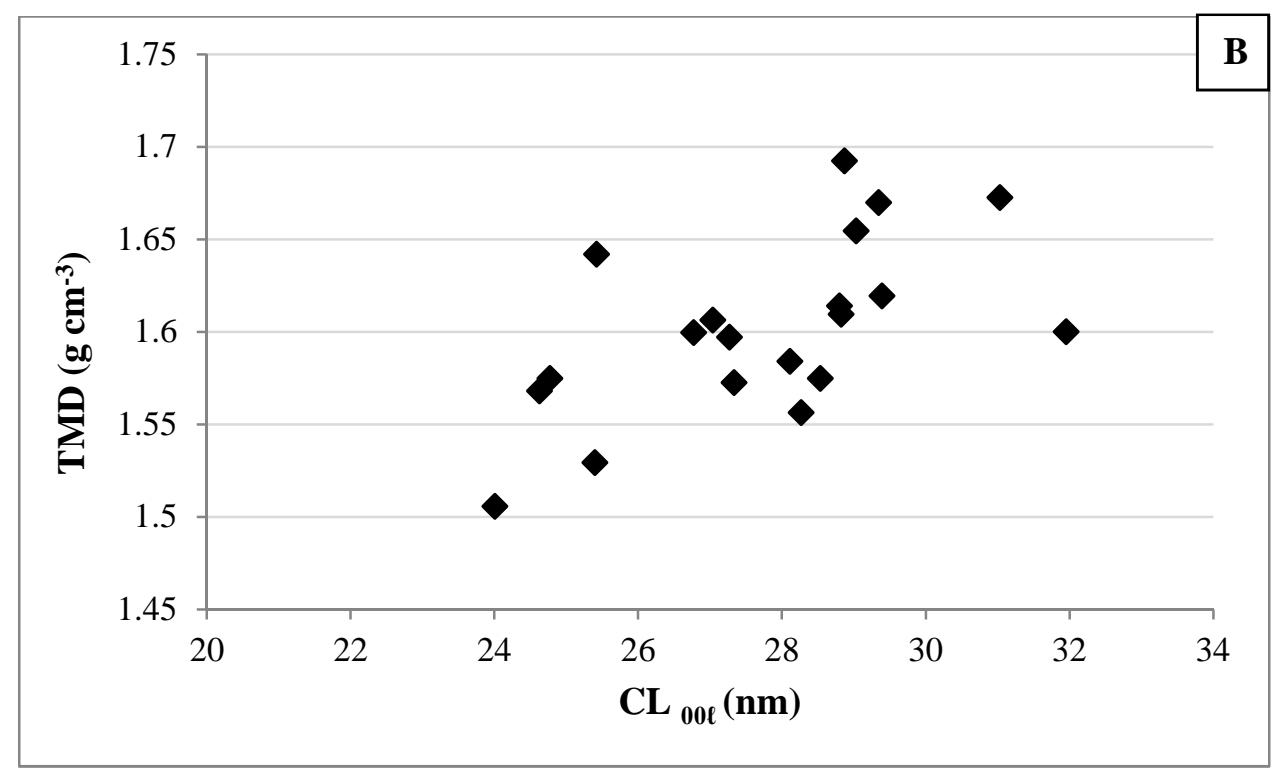

Figure 3: Relationship between microarchitecture properties and coherence length ( $00 \ell$ direction), for fracture specimens, A: TbTh vs CL, B: TMD vs CL. Errors have been excluded from the graphs for clarity.

\section{Discussion}

Although bone performs biologically critical mechanical and homeostatic functions [57], the relationships between its hierarchical constituents are not well understood. The basic chemical composition (non-stoichiometric hydroxyapatite), crystallises into a variable ultrastructure (nano-crystallites) that together with organic components form the fundamental building blocks of bones microarchitecture. Thus, in order to understand mechanical failures associated with compromised bone tissue such as osteoporotic material, it is crucial to understand the fundamental chemistry of the biological mineral.

In contrast to previous studies where the osteoporotic stage of the bone is unknown (e.g. Ovx) [18, 27, 58], our specimens have fractured and therefore present particularly compromised material. Further the power of some previous studies [20, 24, 35] may be insufficient to demonstrate the significant differences observed within our work.

It is important to note here that some of the fundamental mechanical properties of bone may be due to natural engineering processes and cannot be attributed to osteoporosis solely. For example, pre-stressed material components are found within bone and teeth. These stresses not only allow for the structure of bone to perform in its preferred mode of loading [59], but also protect the microstructure from cracking [60]. Collagen dehydration upon mineralisation 
has been found to be at the origin of the compressive pre-strains commonly observed in bone mineral [61]. This creates tension within the collagen fibrils, which has been proposed to offer additional protection against fibril buckling under compression, reducing the danger of bending the fibres, which would lead to fracture [60].

Current literature focuses on the microarchitecture of bone [12 - 14], but few studies have investigated the material crystallographic characteristics of compromised bone mineral [17 21, 24]. The potential relationship between parameters at the nanoscale (i.e. in the mineral chemistry) and the microarchitecture parameters of human bone has, to the authors' knowledge, not previously been directly considered. X-ray coherent scatter provides information specifically regarding the physicochemical characteristics of bone mineral. Differences in the material properties between osteoporotic and 'normal' material, particularly derived from X-ray diffraction, are not consistent across the literature [17, 24, 27 , $35,36]$.

\section{XRD: Crystallinity}

The absolute values for coherence length from this study are consistent with previously published examinations of human bone $[35,62,63]$. We were unable to detect changes in $<00 \ell>$ coherence length or lattice parameters with age. A previous study of Handschin and Stern [64] reported an increase in crystal length up to the age of 25 years old and no significant changes until the age of 50 years old, whereupon the average length decreased. The observed changes at 25 years and 50 years old may not have been apparent in the data presented in our study due to limited power. Handschin and Stern utilised a greater number of specimens $(\mathrm{n}=117)$, across a wider age range $(0-90$ years old $)$. An increase in coherence length along the $\langle 0 \mathrm{k} 0\rangle$ direction, which suggests an increase in crystallite size and a decrease in lattice disorder, was observed with age in the study reported here.

When age matched, significant differences between fracture and non-fracture material were demonstrated. The $<00 \ell>$ coherence length was found to be lower for the fracture group than the non- fracture group $(\mathrm{p}=0.020)$. This is surprising and counter to previous FTIR studies $[18,34]$. However, a possible mechanism to consolidate our view with others is to consider that in OP apatite the carbonate ions preferentially replace those phosphate ions within the most shallow potential wells i.e. those most disordered and measured through the $1020 \mathrm{~cm}^{-1}$ 
IR band, thus causing an apparent increase in crystallinity as measured through the IR crystallinity index (1030/ 1020). The X-ray diffraction coherence length is consequently reduced, and thus the crystallinity appears to decrease. This is further corroborated by a reduction in the ' $a$ ' axis lattice parameter.

Our study therefore suggests a smaller coherence length corresponds to a material which is more susceptible to fracture, suggesting the mechanical strength would be less than that of non-fractured material. Previous studies have suggested that crystal size is related to mechanical strength [65 - 67], and that increased bone mineral crystal size is associated with increased bone fragility [65]. However, after reporting a decrease in crystal thickness with age as crystal length increases, Boskey and Mendelson suggested from their preliminary data that mechanical strength is greater when the average crystallinity is greater [68]. Boskey also argued in favour of an optimal situation in which there is a broad distribution of crystal sizes [19] and Fonseca et al. reported that bone strength is favoured by greater mineral crystal size heterogeneity [11]. Further, Chachra et al. [69] reported that a reduction in crystallite size of bone mineral is associated with a decreased load accommodation and increased fracture risk. This is has also been observed in pathologies such as osteogenesis imperfecta [70].

\section{XRD: Lattice substitutions}

The lattice parameters reported herein are significantly less than those reported previously $[35,36]$. For this study, an internal reference in the form of silicon was employed to ensure accuracy and our values are consistent with levels of carbonate substitution known to occur in bone [37]. Precision was crucial in this study as differences between fracture and non-fracture material were anticipated to be subtle. As previous studies do not use internal references, this could explain the difference in absolute values, although it is possible that other differences such as particle size, tissue source and prior treatment of specimens may also contribute to inter-study inconsistencies with respect to lattice parameters.

The ' $a$ ' axis lattice parameter values, which are rarely reported in the literature for bone material, were found to be lower $(\mathrm{p}=0.002)$ for the fracture group in comparison to the nonfracture group. In contrast, Mkukuma et al reported no difference between osteoporotic material and 'normal' tissue when considering lattice parameters [35]. However, the relative low power (low sample numbers) may not have revealed the relatively modest differences $(<$ 
$1 \%$ ) between osteoporotic and 'normal' tissue. The stoichiometric 'a' axis lattice parameter value for hydroxyapatite is reported as $9.42 \AA$ [36]. The data reported herein suggests nonfracture material is more stoichiometric than the fracture material, and therefore more chemically stable. Changes to lattice parameters values are caused by ionic exchanges and vacancies which induce strain into the lattice. This changes the characteristics of the apatite which are critical to crystallite size and dissolution rate [71]. Greater dissolution rates, for example, will be observed for mineral lattices which are highly strained and therefore less stoichiometric. As osteoporosis is a condition associated with bone loss and perhaps greater turnover, the more soluble lattice structure is probably a more likely state for the mineral being formed. The reduced lattice parameters calculated for the fracture group is consistent with the carbonate to phosphate ratios calculated with FTIR, as many studies have shown with increasing $B$-type carbonate, the ' $a$ ' axis lattice parameter is reduced [37, 72]. No difference was observed for the ' $c$ ' axis lattice parameters between the two groups. Changes to the unit cell through ionic substitutions has previously been shown to have more of an effect on the ' $a$ ' axis in comparison to the 'c' axis [37], which is evident when considering the influence of carbonate substitute on the lattice parameters. LeGeros reported a systematic change in ' $a$ ' that was 2.5 times that of ' $c$ ' for an equivalent increase in amount of B-type carbonate substitution [37]. Therefore we propose that the sensitivity of our study is too low to detect corresponding significant changes to the ' $c$ ' axis.

\section{FTIR}

The material characteristics obtained from FTIR demonstrate an increase in the mineral to organic ratio with increasing age. This may suggest an increase in the amount of phosphate and/or a decrease in collagen (measured through the amide vibrational peak). An increase in mineral content with age has previously been reported [19], as well as a decrease in collagen content [73]. When age matched, the mineral to organic ratio was not significantly different between the fracture and non-fracture group, although the values for the fracture group were lower. In contrast, previous studies have shown a decrease in the mineral to organic ratio in ovariectomized animal and osteoporotic human tissue [18, 30, 33, 45, 74], suggesting either a lower mineral content and/ or a greater collagen content. The consensus tends to be that in osteoporotic bone, a decrease in mineral content is observed $[18,19]$, resulting in a reduction in mechanical strength [11]. 
Although carbonate incorporation has been reported to increase $[64,75,76]$ and decrease $[45$, 77] with age, no correlation with age was observed for the carbonate to phosphate ratio values in this study. This is consistent with [66], who found carbonate incorporation remained constant after 45 years old. When age matched, a mean difference of $0.002 \pm$ 0.0004 was observed for the carbonate to phosphate ratios between the two groups. The average value for the fracture group was greater in comparison to the non-fracture group $(\mathrm{p}=$ 0.000). This suggests greater carbonate content in the fracture material in comparison to the non-fracture material and/ or less phosphate. A higher carbonate to phosphate ratio in the fracture material is consistent with previous studies [18, 28, 34]. This increase is consistent with the data reported here, where a $\sim 11 \%$ increase in the carbonate to phosphate ratio was observed for the fracture material.

In general, it is considered that newer bone contains a large quantity of carbonate and is characterised by smaller crystals $[38,78]$. In an accelerated turnover system, the consumption rate of the more mature tissue (i.e. that preferentially targeted for remodelling) is enhanced [79]. Crystallite populations then become biased towards reduced average dimensions, larger specific surface areas and greater amounts of carbonate. The data presented here is consistent with this model, as the coherence length values are lower for the fracture material whilst the carbonate to phosphate ratio was greater.

\section{Evaluation}

The results from this study must be seen in the context of previous work and some speculation offered for apparent inconsistencies. There is clear evidence of significant differences in the physicochemical characteristics of bone mineral from different sample sites. For example, Gourion-Arsiquaud et al. reported greater cortical mineral/organic and trabecular crystallinity values associated with increased fracture risk when iliac crest specimens were analysed [32]. However, more recently, when investigating material properties of femoral neck specimens, a decrease in the mineral: organic ratio for both cortical and trabecular fractured bone was observed whilst no change in crystallinity was reported [33] by the same research group. Such differences can also be found between local geographic anatomies as demonstrated by Donnelly et al. [80]. Thus, it may be inappropriate to directly compare our findings with those from studies employing femoral neck and iliac 
crest tissues as the physicochemical nature of the materials from different sites appear significantly different.

Specific analytical differences may also compromise direct comparisons with other studies (and between previous studies). In particular, when considering determinations of 'crystallinity', estimates derived from FTIR and those from XRD may superficially appear to be inconsistent. FTIR methods determine crystallinity specifically from quantification of $\mathrm{PO}_{4}$ site disorder averaged over all crystallographic directions. In contrast, our diffraction based crystallinity measurement is fundamentally different in that it is confined to disorder within one crystallographic direction and concerns all phenomena that reduce disorder in this direction [81]. A comparison between spectroscopic and diffraction estimates of crystallinity within biological apatites has previously highlighted inconsistencies between the results of the two approaches [82]. Thus at least for this parameter, direct comparisons between previously FTIR studies and ours may not be appropriate. For this and other characteristics, apparent inconsistencies between previous work and ours may also be partly as a result of sample preparation and sampling differences. Processing involving aqueous solutions has been shown to modify the physicochemical characteristics of bone [83-85] although in our study the tissues were frozen. Our approach of quadrant sampling randomisation would have increased the variability in any of the characteristics measured and thus, given the previously reported variation between quadrant values [33], we may have expected a reduction in the power of our experiments.

\section{Architecture}

This study has also examined relationships between the material characteristics of bone and its corresponding architectural properties, as there is significant evidence from previous studies that bone mechanical properties (e.g. fragility) are affected by physicochemical material features [18, $49-53,65-68]$. In this work, the bone mineral chemical parameters have been compared and the study provides a novel materials science insight into the relationship between bone physicochemistry at the nanoscale and the architecture of the bone at the microscale. The results suggest that there is a relationship between the material characteristics (in particular the coherence length) and the microarchitecture properties. Coherence length values are a quantification of crystallite disorder (size and microstrain). An 
increase in microstrain can indicate ionic substitutions and vacancies. This change can also have an effect on crystallite dimensions and other factors including solubility. Previous studies have shown the solubility of apatite increases as the lattice microstrain is increased [71]. Further, disorder within the apatite lattice, has been proposed as a fundamental contributor to bone mechanical compromise for more than three decades [65]. In this study, with increasing coherence length values, increases in TbTh, TMD and BV/TV were observed. It is proposed that bone apatite with higher coherence length values represents a more stable, less soluble material and therefore should be associated with increased amounts of bone mineral as reflected by the increase BV/TV, BMD and TbTh.

\section{Conclusion}

The principal main aim of this study was to investigate bone 'quality' in terms of mineral chemistry and organic content of fractured and non-fractured human material. Age related changes for the non-fracture material were also investigated. The relationship between the bone mineral chemical characteristics and the microarchitecture parameters was also examined. As shown through statistical analysis, the coherence length $(<00 \ell>)$, 'a' axis lattice parameters and carbonate to phosphate ratio values (when age matched) were different between fracture and non-fracture material from female donors. The study has also shown an increase in crystallite size and an decrease in lattice disorder ([0k0]) as well as an increase in the amount of phosphate and/or a decrease in collagen occurs with age for non-fracture material. It is proposed the data reported here suggests osteoporosis may not simply be an accelerated aging process when considering mineral chemistry and organic content, but there are fundamental chemical differences between fracture and non-fracture material not found with age. It is interesting to speculate that there may be a relationship between the mineral properties of bone at the ultrastructure level and the microarchitectural properties of trabecular bone.

\section{Acknowledgements}

This programme of work is funded by an Engineering and Physical Sciences Research Council (grant: EP/K020196/1 Point-of-Care High Accuracy Fracture Risk Prediction). The 
authors acknowledge the support provided by the UK Department of Transport under the BOSCOS (Bone Scanning for Occupant Safety) project for which the human material was obtained in the Gloucester and Cheltenham NHS Trust hospitals under ethical consent (BOSCOS - Mr. Curwen CI REC ref. 01/179G) and were from individuals who either consented themselves or where their next of kin signed an informed consent. The consents pertained to the use in relation to diagnostic purposes and basic bone research. The authors also recognise support from the Victorian Institute of Forensic Pathology, which later changed its name to the Victorian Institute of Forensic Medicine (VIFM). All donors from this source were coronial cases and had therefore died suddenly and unexpectedly frequently as result of accidents. Permission to remove the tissue for research was obtained from the next of kin in strict accordance with Australian National Health and Medical Research Council guidelines and prevailing local legislation. The approach to the families was made by trained transplant coordinators who also administered a limited questionnaire to investigate the medical history of the deceased where this was known. Ethics approval was sought and obtained for our program of studies into age-related changes to bone both at the VIFM and at the University of Melbourne. Later, when material was no longer being collected at autopsy, responsibility for ethical oversight was transferred exclusively to The University of Melbourne on 28th April 2011 ethics ID 1135392. This is continuing. 


\section{References}

[1] Van Staa TP, Dennison EM, Leufkens HG, Cooper C. Epidemiology of fractures in England and Wales. Bone. 2001 Dec 31;29(6):517-22.

[2] Keene GS, Parker MJ, Pryor GA. Mortality and morbidity after hip fractures. Bmj. 1993 Nov 13;307(6914):1248-50.

[3] Cooper C, Atkinson EJ, Jacobsen SJ, O'Fallon WM, Melton LJ. Population-based study of survival after osteoporotic fractures. American Journal of Epidemiology. 1993 May $1 ; 137(9): 1001-5$.

[4]. Leibson CL, Tosteson AN, Gabriel SE, Ransom JE, Melton LJ. Mortality, disability, and nursing home use for persons with and without hip fracture: a population-based study. Journal of the American Geriatrics Society. 2002 Oct 1;50(10):1644-50.

[5] Kanis JA, Delmas P, Burckhardt P, Cooper C, Torgerson DO. Guidelines for diagnosis and management of osteoporosis. Osteoporosis International. 1997 Jul 1;7(4):390-406.

[6] Marshall D, Johnell O, Wedel H. Meta-analysis of how well measures of bone mineral density predict occurrence of osteoporotic fractures. Bmj. 1996 May 18;312(7041):1254-9.

[7] Wainwright SA, Marshall LM, Ensrud KE, Cauley JA, Black DM, Hillier TA, Hochberg MC, Vogt MT, Orwoll ES. Hip fracture in women without osteoporosis. The Journal of Clinical Endocrinology \& Metabolism. 2005 May 1;90(5):2787-93.

[8] Siris ES, Chen YT, Abbott TA, Barrett-Connor E, Miller PD, Wehren LE, Berger ML. Bone mineral density thresholds for pharmacological intervention to prevent fractures. Archives of Internal Medicine. 2004 May 24;164(10):1108-12.

[9] Kanis JA, Johnell O, Odén A, Johansson H, McCloskey E. FRAX ${ }^{\mathrm{TM}}$ and the assessment of fracture probability in men and women from the UK. Osteoporosis International. $2008 \mathrm{Apr}$ 1;19(4):385-97.

[10] Farlay, D Boivin, G Bone Mineral Quality, in: Osteoporosis, Y. Dionyssiotis, ed., InTech, 2012, pp.3-32. doi: $\underline{10.5772 / 29091}$

[11] Fonseca H, Moreira-Gonçalves D, Coriolano HJ, Duarte JA. Bone quality: The determinants of bone strength and fragility. Sports Medicine. 2014 Jan 1;44(1):37-53.

[12] Kijowski R, Tuite M, Kruger D, Munoz Del Rio A, Kleerekoper M, Binkley N. Evaluation of trabecular microarchitecture in nonosteoporotic postmenopausal women with and without fracture. Journal of Bone and Mineral Research. 2012 Jul 1;27(7):1494-500.

[13] Milovanovic P, Djonic D, Marshall RP, Hahn M, Nikolic S, Zivkovic V, Amling M, Djuric M. Micro-structural basis for particular vulnerability of the superolateral neck trabecular bone in the postmenopausal women with hip fractures. Bone. 2012 Jan 31;50(1):63-8. 
[14] Djuric M, Zagorac S, Milovanovic P, Djonic D, Nikolic S, Hahn M, Zivkovic V, Bumbasirevic M, Amling M, Marshall RP. Enhanced trabecular micro-architecture of the femoral neck in hip osteoarthritis vs. healthy controls: a micro-computer tomography study in postmenopausal women. International Orthopaedics. 2013 Jan 1;37(1):21-6.

[15] Krug R, Burghardt AJ, Majumdar S, Link TM. High-resolution imaging techniques for the assessment of osteoporosis. Radiologic Clinics of North America. 2010 May 31;48(3):601-21.

[16] Harvey NC, Glüer CC, Binkley N, McCloskey EV, Brandi ML, Cooper C, Kendler D, Lamy O, Laslop A, Camargos BM, Reginster JY. Trabecular bone score (TBS) as a new complementary approach for osteoporosis evaluation in clinical practice. Bone. 2015 Sep 30;78:216-24.

[17] Thompson DD, Posner AS, Laughlin WS, Blumenthal NC. Comparison of bone apatite in osteoporotic and normal Eskimos. Calcified Tissue International. 1983 Dec 1;35(1):392-3.

[18] Gadeleta SJ, Boskey AL, Paschalis E, Carlson C, Menschik F, Baldini T, Peterson M, Rimnac CM. A physical, chemical, and mechanical study of lumbar vertebrae from normal, ovariectomized, and nandrolone decanoate-treated cynomolgus monkeys (Macaca fascicularis). Bone. 2000 Oct 31;27(4):541-50.

[19] Boskey A. Bone mineral crystal size. Osteoporosis International. 2003 Sep 1;14:S16-21.

[20] Rubin MA, Jasiuk I, Taylor J, Rubin J, Ganey T, Apkarian RP. TEM analysis of the nanostructure of normal and osteoporotic human trabecular bone. Bone. 2003 Sep $30 ; 33(3): 270-82$.

[21] Yerramshetty J, Akkus O (2013) Changes in cortical bone mineral and microstructure with aging and osteoporosis. In: Silva MJ (ed) Skeletal Aging and Osteoporosis. Biomechanics and Mechanobiology. Springer, Heidelberg, pp 105 - 131

[22] Boskey AL, Donnelly E, Boskey E, Spevak L, Ma Y, Zhang W, Lappe J, Recker RR. Examining the Relationships Between Bone Tissue Composition, Compositional Heterogeneity, and Fragility Fracture: A Matched Case-Controlled FTIRI Study. Journal of Bone and Mineral Research. 2015 Dec 1.

[23] Nyman JS, Granke M, Singleton RC, Pharr GM. Tissue-Level Mechanical Properties of Bone Contributing to Fracture Risk. Current osteoporosis reports. 2016 Jun 4:1-3.

[24] Sastry TP, Chandrsekaran A, Sundaraseelan J, Ramasastry M, Sreedhar R. Comparative study of some physico-chemical characteristics of osteoporotic and normal human femur heads. Clinical Biochemistry. 2007 Aug 31;40(12):907-12.

[25] Doublier, A., Farlay, D., Jaurand, X., Vera, R. and Boivin, G., 2013. Effects of strontium on the quality of bone apatite crystals: a paired biopsy study in postmenopausal osteoporotic women. Osteoporosis International, 24(3), pp.1079-1087. 
[26] Huang RY, Miller LM, Carlson CS, Chance MR. In situ chemistry of osteoporosis revealed by synchrotron infrared microspectroscopy. Bone. 2003 Oct 31;33(4):514-21.

[27] Lundon K, Dumitriu M, Grynpas M. The long-term effect of ovariectomy on the quality and quantity of cancellous bone in young macaques. Bone and mineral. 1994 Feb $28 ; 24(2): 135-49$.

[28] McCreadie BR, Morris MD, Chen TC, Rao DS, Finney WF, Widjaja E, Goldstein SA. Bone tissue compositional differences in women with and without osteoporotic fracture. Bone. 2006 Dec 31;39(6):1190-5.

[29] Paschalis EP, Fratzl P, Gamsjaeger S, Hassler N, Brozek W, Eriksen EF, Rauch F, Glorieux FH, Shane E, Dempster D, Cohen A. Aging Versus Postmenopausal Osteoporosis: Bone Composition and Maturation Kinetics at Actively-Forming Trabecular Surfaces of Female Subjects Aged 1 to 84 Years. Journal of Bone and Mineral Research. 2015 Sep 1.

[30] Boskey AL, DiCarlo E, Paschalis E, West P, Mendelsohn R. Comparison of mineral quality and quantity in iliac crest biopsies from high-and low-turnover osteoporosis: an FT-IR microspectroscopic investigation. Osteoporosis International. 2005 Dec 1;16(12):2031-8.

[31] Ruppel ME, Burr DB, Miller LM. Chemical makeup of microdamaged bone differs from undamaged bone. Bone. 2006 Aug 31;39(2):318-24.

[32] Gourion-Arsiquaud S, Faibish D, Myers E, Spevak L, Compston J, Hodsman A, Shane E, Recker RR, Boskey ER, Boskey AL. Use of FTIR spectroscopic imaging to identify parameters associated with fragility fracture. Journal of bone and mineral research. 2009 Sep 1;24(9):1565-71.

[33] Gourion-Arsiquaud S, Lukashova L, Power J, Loveridge N, Reeve J, Boskey AL. Fourier transform infrared imaging of femoral neck bone: Reduced heterogeneity of mineralto-matrix and carbonate-to-phosphate and more variable crystallinity in treatment-naive fracture cases compared with fracture-free controls. Journal of Bone and Mineral Research. 2013 Jan 1;28(1):150-61.

[34] Faibish D, Ott SM, Boskey AL. Mineral changes in osteoporosis a review. Clinical Orthopaedics and Related Research. 2006 Feb;443:28.

[35] Mkukuma LD, Imrie CT, Skakle JM, Hukins DW, Aspden RM. Thermal stability and structure of cancellous bone mineral from the femoral head of patients with osteoarthritis or osteoporosis. Annals of the Rheumatic Diseases. 2005 Feb 1;64(2):222-5.

[36] Handschin RG, Stern WB. Crystallographic lattice refinement of human bone. Calcified Tissue International. 1992 Aug 1;51(2):111-20.

[37] Zapanta-LeGeros R. Effect of carbonate on the lattice parameters of apatite. Nature, 1965 April, 206, 403 - 404, doi:10.1038/206403a0 
[38] Rey C, Collins B, Goehl T, Dickson IR, Glimcher MJ. The carbonate environment in bone mineral: a resolution-enhanced Fourier transform infrared spectroscopy study. Calcified Tissue International. 1989 May 1;45(3):157-64.

[39] Schwartsmann CR, Spinelli LD, Sotomayor MY, Yépez AK, Boschin LC, Silva MF. Bleeding of Femoral Head During Total Hip Arthroplasty for Osteoporosis Acta ortopedica brasileira. 2015 Oct;23(5):268-70.

[40] Abraham E, Gonzalez MH, Pratap S, Amirouche F, Atluri P, Simon P. Clinical implications of anatomical wear characteristics in slipped capital femoral epiphysis and primary osteoarthritis. Journal of Pediatric Orthopaedics. 2007 Oct 1;27(7):788-95.

[41] Greenwood C, Clement JG, Dicken AJ, Evans JP, Lyburn ID, Martin RM, Rogers KD, Stone N, Adams G, Zioupos P. The micro-architecture of human cancellous bone from fracture neck of femur patients in relation to the structural integrity and fracture toughness of the tissue. Bone Reports. 2015 Dec 31;3:67-75.

[42] Cook RB, Zioupos P. The fracture toughness of cancellous bone. Journal of biomechanics. 2009 Sep 18;42(13):2054-60.

[43] Cook RB, Curwen C, Tasker T, Zioupos P. Fracture toughness and compressive properties of cancellous bone at the head of the femur and relationships to non-invasive skeletal assessment measurements. Medical engineering \& physics. 2010 Nov 30;32(9):9917.

[44] E.F. Kaelble (Ed.), Handbook of X-rays for Diffraction, Emission, Absorption, and Microscopy, McGraw-Hill, New York, 1967, pp. 17-25.

[45] Paschalis EP, Betts F, DiCarlo E, Mendelsohn R, Boskey AL. FTIR microspectroscopic analysis of normal human cortical and trabecular bone. Calcified Tissue International. 1997 Dec 1;61(6):480-6.

[46] Paschalis EP, Mendelsohn R, Boskey AL. Infrared assessment of bone quality: a review. Clinical Orthopaedics and Related Research. 2011 Aug 1;469(8):2170-8.

[47] Pienkowski D, Doers TM, Monier-Faugere MC, Geng Z, Camacho NP, Boskey AL, Malluche HH. Calcitonin alters bone quality in beagle dogs. Journal of Bone and Mineral Research. 1997 Nov 1;12(11):1936-43.

[48] Bohic S, Heymann D, Pouëzat JA, Gauthier O, Daculsi G. Transmission FT-IR microspectroscopy of mineral phases in calcified tissues. Comptes Rendus de l'Académie des Sciences-Series III-Sciences de la Vie. 1998 Oct 31;321(10):865-76.

[49] Turan B, Bayari S, Balcik C, Severcan F, Akkas N. A biomechanical and spectroscopic study of bone from rats with selenium deficiency and toxicity. Biometals. 2000 Jun $1 ; 13(2): 113-21$. 
[50] Kohles SS, Martinez DA. Elastic and physicochemical relationships within cortical bone. Journal of Biomedical Materials Research. 2000 Mar 15;49(4):479-88.

[51] Freeman JJ, Wopenka B, Silva MJ, Pasteris JD. Raman spectroscopic detection of changes in bioapatite in mouse femora as a function of age and in vitro fluoride treatment. Calcified Tissue International. 2001 Mar 1;68(3):156-62.

[52] Camacho NP, Hou L, Toledano TR, Ilg WA, Brayton CF, Raggio CL, Root L, Boskey AL. The material basis for reduced mechanical properties in oim mice bones. Journal of Bone and Mineral Research. 1999 Feb 1;14(2):264-72.

[53] Landete-Castillejos T, Currey JD, Estevez JA, Gaspar-López E, Garcia A, Gallego L. Influence of physiological effort of growth and chemical composition on antler bone mechanical properties. Bone. 2007 Nov 30;41(5):794-803.

[54] Yao F, LeGeros RZ. Carbonate and fluoride incorporation in synthetic apatites: Comparative effect on physico-chemical properties and in vitro bioactivity in fetal bovine serum. Materials Science and Engineering: C. 2010 Apr 6;30(3):423-30.

[55] Baig AA, Fox JL, Young RA, Wang Z, Hsu J, Higuchi WI, Chhettry A, Zhuang H, Otsuka M. Relationships among carbonated apatite solubility, crystallite size, and microstrain parameters. Calcified Tissue International. 1999 May 1;64(5):437-49.

[56] Tang R, Henneman ZJ, Nancollas GH. Constant composition kinetics study of carbonated apatite dissolution. Journal of Crystal Growth. 2003 Mar 31;249(3):614-24.

[57] Florencio-Silva R, Sasso GR, Sasso-Cerri E, Simões MJ, Cerri PS. Biology of bone tissue: structure, function, and factors that influence bone cells. BioMed Research International. 2015 Jan 1;2015.

[58] Orkoula MG, Vardaki MZ, Kontoyannis CG. Study of bone matrix changes induced by osteoporosis in rat tibia using raman spectroscopy. Vibrational Spectroscopy. 2012 Nov 30;63:404-8.

[59] Gordon JE. Structures, or, Why things don't fall down. Da Capo Press; 2003.

[60] Forien JB, Fleck C, Cloetens P, Duda G, Fratzl P, Zolotoyabko E, Zaslansky P. Compressive Residual Strains in Mineral Nanoparticles as a Possible Origin of Enhanced Crack Resistance in Human Tooth Dentin. Nano letters. 2015 May 29;15(6):3729-34.

[61] Bertinetti L, Masic A, Schuetz R, Barbetta A, Seidt B, Wagermaier W, Fratzl P. Osmotically driven tensile stress in collagen-based mineralized tissues. Journal of the mechanical behavior of biomedical materials. 2015 Dec 31;52:14-21.

[62] Holden JL, Clement JG, Phakey PP. Age and temperature related changes to the ultrastructure and composition of human bone mineral. Journal of Bone and Mineral Research. 1995 Sep 1;10(9):1400-9. 
[63] Beckett S, Rogers KD, Clement JG. Inter-Species Variation in Bone Mineral Behavior upon Heating. Journal of Forensic Sciences. 2011 May 1;56(3):571-9.

[64] Handschin RG, Stern WB. X-ray diffraction studies on the lattice perfection of human bone apatite (Crista iliaca). Bone. 1995 Apr 30;16(4):S355-63.

[65] Chatterji S, Wall JC, Jeffery JW. Age-related changes in the orientation and particle size of the mineral phase in human femoral cortical bone. Calcified Tissue International. 1981 Dec 1;33(1):567-74.

[66] Akkus O, Adar F, Schaffler MB. Age-related changes in physicochemical properties of mineral crystals are related to impaired mechanical function of cortical bone. Bone. 2004 Mar 31;34(3):443-53.

[67] Turner CH, Garetto LP, Dunipace AJ, Zhang W, Wilson ME, Grynpas MD, Chachra D, McClintock R, Peacock M, Stookey GK. Fluoride treatment increased serum IGF-1, bone turnover, and bone mass, but not bone strength, in rabbits. Calcified Tissue International. 1997 Jul 1;61(1):77-83.

[68] Boskey A, Mendelsohn R. Infrared analysis of bone in health and disease. Journal of Biomedical Optics. 2005 May 1;10(3):031102-9.

[69] Chachra D, Turner CH, Dunipace AJ, Grynpas MD. The effect of fluoride treatment on bone mineral in rabbits. Calcified Tissue International. 1999 Apr 1;64(4):345-51.

[70] Vetter U, Eanes ED, Kopp JB, Termine JD, Robey PG. Changes in apatite crystal size in bones of patients with osteogenesis imperfecta. Calcified Tissue International. $1991 \mathrm{Jul}$ 1;49(4):248-50.

[71] Wopenka B, Pasteris JD. A mineralogical perspective on the apatite in bone. Materials Science and Engineering: C. 2005 Apr 28;25(2):131-43.

[72] Nelson DG, Featherstone JD. Preparation, analysis, and characterization of carbonated apatites. Calcified Tissue International. 1981 Dec;34:S69-81.

[73] Bailey AJ, Sims TJ, Ebbesen EN, Mansell JP, Thomsen JS, Mosekilde L. Age-related changes in the biochemical properties of human cancellous bone collagen: relationship to bone strength. Calcified tissue international. 1999 Sep 1;65(3):203-10.

[74] Burket JC, Brooks DJ, MacLeay JM, Baker SP, Boskey AL, van der Meulen MC. Variations in nanomechanical properties and tissue composition within trabeculae from an ovine model of osteoporosis and treatment. Bone. 2013 Jan 31;52(1):326-36.

[75] Legros R, Balmain N, Bonel G. Age-related changes in mineral of rat and bovine cortical bone. Calcified Tissue International. 1987 Sep 1;41(3):137-44. 
[76] Rey C, Renugopalakrishman V, Collins B, Glimcher MJ. Fourier transform infrared spectroscopic study of the carbonate ions in bone mineral during aging. Calcified Tissue International. $1991 \mathrm{Jul} \mathrm{1;49(4):251-8.}$

[77] Ouyang H, Sherman PJ, Paschalis EP, Boskey AL, Mendelsohn R. Fourier transform infrared microscopic imaging: effects of estrogen and estrogen deficiency on fracture healing in rat femurs. Applied Spectroscopy. 2004 Jan 1;58(1):1-9.

[78] Miller LM, Vairavamurthy V, Chance MR, Mendelsohn R, Paschalis EP, Betts F, Boskey AL. In situ analysis of mineral content and crystallinity in bone using infrared microspectroscopy of the $v 4$ PO 4 3- vibration. Biochimica et Biophysica Acta (BBA)-General Subjects. 2001 Jul 2;1527(1):11-9.

[79] Clarke B. Normal bone anatomy and physiology. Clinical Journal of the American Society of Nephrology. 2008 Nov 1;3(Supplement 3):S131-9.

[80] Donnelly, E., Meredith, D.S., Nguyen, J.T. and Boskey, A.L., 2012. Bone tissue composition varies across anatomic sites in the proximal femur and the iliac crest. Journal of Orthopaedic Research, 30(5), pp.700-706.

[81] Rogers, K., Beckett, S., Kuhn, S., Chamberlain, A. and Clement, J., 2010. Contrasting the crystallinity indicators of heated and diagenetically altered bone mineral. Palaeogeography, Palaeoclimatology, Palaeoecology, 296(1), pp.125-129.

[82] Wopenka, B., Pasteris, J.D. and Rogers, K., 2002, October. Are the Properties of Bioapatite Different in Bone with Different Percent Mineralization? In 2002 Denver Annual Meeting.

[83] Landis, W.J. and Glimcher, M.J., 1978. Electron diffraction and electron probe microanalysis of the mineral phase of bone tissue prepared by anhydrous techniques. Journal of ultrastructure research, 63(2), pp.188-223.

[84] McKee, M.D., Nanci, A., Landis, W.J., Gotoh, Y., Gerstenfeld, L.C. and Glimcher, M.J., 1991. Effects of fixation and demineralization on the retention of bone phosphoprotein and other matrix components as evaluated by biochemical analyses and quantitative immunocytochemistry. Journal of Bone and Mineral Research, 6(9), pp.937-945.

[85] Aparicio, S., Doty, S.B., Camacho, N.P., Paschalis, E.P., Spevak, L., Mendelsohn, R. and Boskey, A.L., 2002. Optimal methods for processing mineralized tissues for Fourier transform infrared microspectroscopy.Calcified tissue international, 70(5), pp.422-429. 